\title{
CORRESPONDENCE
}

\section{PATHOGENIC FUNGI IN BIRD EXCRETA: A FORGOTTEN PUBLIC HEALTH PROBLEM}

October 31,2014

\section{Dear editor,}

The recent report on "fungi in bird excreta" is very interesting ${ }^{1}$. MENDES et al. found many contaminated fungi in the samples, and mentioned for the requirement for public health concern preventive measures, such as "proper cleaning of cages". In fact, the concern of fungi contamination in bird excreta should be raised. It is usually forgotten. In uncaged bird, the contamination might be more problematic since it is not possible to effectively clean. In our experience, the examination of bird excreta from public yard, showed that up to $9.09 \%$ of the samples were contaminated with pathogenic fungi. To set a system to control bird excreta and surveillance of pathogen contamination in excreta should be an important topic for any community.

(1) Sanitation 1 Medical Academic Center, Bangkok Thailand

(2) Visiting professor, Hainan Medical University, China

Correspondence to: Beuy Joob Sanitation 1 Medical Academic Center, Bangkok Thailand

E-mail: wviroj@yahoo.com

\section{REFERENCES}

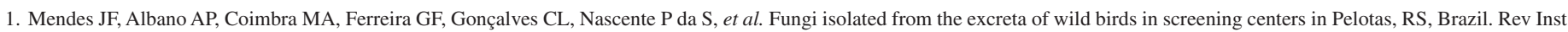
Med Trop Sao Paulo. 2014;56:525-8.

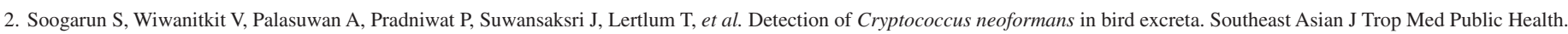
2006;37:768-70. 